\title{
Impaired Synthesis of Lipoxygenase Products in Glutathione Synthetase Deficiency
}

\author{
ERTAN MAYATEPEK, GEORG F. HOFFMANN, BIRGIT CARLSSON, AGNE LARSSON, AND \\ KATJA BECKER \\ University' Children's Hospital, Heidelberg, Germany [E.M., G.F.H., K.B.J, and Department of Pediatrics, \\ University Children's Hospital, Uppsala, Swe'den [B.C., A.L.]
}

\begin{abstract}
Glutathione synthetase deficiency (GSD) is an inborn error of glutathione (GSII) metabolism leading to a generalized intracellular GSH deficiency. Because GSH is required for leukotriene $\mathrm{C}_{4}\left(\mathrm{LTC}_{4}\right)$ synthesis, we studied synthesis and metabolism of several lipoxygenase products in two patients with GSD by radio-HPLC, UV spectrophotometry, and enzyme immunoassays. In both patients, $\mathrm{LTC}_{4}$ synthesis was significantly decreased in calcium ionophore-stimulated neutrophils (up to $0.4 \mathrm{ng} /$ $10^{6}$ cells; controls, $5.0 \pm 0.9$ ) and monocytes (up to $3.6 \mathrm{ng} /$ $10^{6}$ cells; controls, $30.2 \pm 3.3$ ). LTB $_{4}$ synthesis was about seven times higher in GSD cells compared with controls, whereas synthesis of other 5-, 12-, and 15-lipoxygenase products and prostaglandin $E_{2}$ was not affected. Neutrophils and monocytes from both patients showed a marked reduction in capacity to form $\left[{ }^{3} \mathrm{H}\right] \mathrm{LTC}_{4}$ from $\left.\left.\right|^{3} \mathrm{H}\right] \mathrm{LTA} \mathrm{A}_{4}$ (9-14\% of control values). Urinary $\mathrm{LTE}_{4}$ was finally found to be 50 -fold lower in GSD, reflecting a decreased synthesis of cysteinyl LT in vivo. GSD may serve as a unique model for the linkage between LT synthesis and GSH metabolism in vivo. (Pediatr Res 35: 307-310, 1994)
\end{abstract}

\section{Abbreviations}

GSD, glutathione synthetase deficiency

LT, leukotriene

PG, prostaglandin

GSH, glutathione

HETE, hydroxyeicosatetraenoic acid

GSD is an inborn error of GSH metabolism (1-4). The disease is associated with severe metabolic acidosis, hemolytic anemia, and progressive affection of the CNS $(3,4)$. GSD is associated with massive renal excretion of 5-oxoproline. As a consequence of the block at this step in the $\gamma$-glutamyl cycle, the enzyme defect leads to a generalized intracellular GSH deficiency $(3,4)$. The tripeptide GSH is one of the most important nonenzymatic intracellular antioxidants, protecting cells from toxic effects of reactive oxygen species (5) and participating in $\mathrm{LTC}_{4}$ synthesis $(6,7)$.

LT are lipid mediators derived in cells such as neutrophils and macrophages from the oxidative metabolism of arachidonic acid by action of the 5-lipoxygenase system $(6,7)$. The unstable intermediate $\mathrm{LTA}_{4}$ can be converted by an epoxide hydrolase to $\mathrm{LTB}_{4}$ or conjugated with GSH to form $\mathrm{LTC}_{4}$. In the circulation

Received March 4, 1993; accepted September 30, 1993.

Correspondence and reprint requests: Ertan Mayatepek, M.D., University Children's Hospital, Im Neuenheimer Feld 150, 69120 Heidelberg. Germany.

Supported by the Deutsche Forschungsgemeinschaft (Ho966/2-3), by a grant from the Swedish Medical Research Council (no, 4792), and by the Fonds der Chemischen Industric, Frankfurt, Germany.
$\mathrm{LTC}_{4}$ is rapidly metabolized to $\mathrm{LTE}_{4}$, which is excreted into the urine $(8,9)$. LT can act as potent chemotactic substances $\left(\mathrm{LTB}_{4}\right)$ or cause smooth-muscle contraction and vascular leakage ( $\mathrm{LTC}_{4}$, $\left.\mathrm{LTD}_{4}, \mathrm{LTE}_{4}\right)(6,7)$.

Although GSH represents a cosubstrate for $\mathrm{LTC}_{4}$ synthesis, no data exist regarding the level of intracellular GSH required for endogenous $\mathrm{LTC}_{4}$ formation. In addition, $\mathrm{GSH}$ is needed for the formation of the cyclooxygenase product $\mathrm{PGE}_{2}(10)$.

The present study was carried out to gain insight into the linkage between the metabolism of GSH and lipoxygenase products in GSD. Synthesis of several lipoxygenase products and $\mathrm{PGE}_{2}$ in neutrophils and monocytes, their capacity to metabolize $\mathrm{LTA}_{4}$ into $\mathrm{LTC}_{4}$, and urinary $\mathrm{LTE}_{4}$ excretion were analyzed in two patients with GSD.

\section{MATERIALS AND METHODS}

Patients. Patient 1 , a girl born at 39 wk gestation by cesarean section, was the first child of nonconsanguinous parents. On the second day of life, clinical and laboratory signs of generalized infection and severe metabolic acidosis developed. The infant responded well to i.v. treatment with antibiotics and sodium bicarbonate. However, after this therapy was terminated at $11 \mathrm{~d}$ of age, metabolic acidosis reappeared, and since then oral administration of sodium bicarbonate has been continuously required. At the time blood and urine samples were obtained, the child was 3 y of age. Until then she had a normal psychomotoric development without any neurologic deficit.

Patient 2, a boy born at 36 wk gestation, was the fourth child of nonconsanguinous parents. Apgar scores were 7 and 8 , respectively. Severe metabolic acidosis became apparent on the first day of life, and substitution with sodium bicarbonate was started. In the first week of life, hemolytic anemia developed, requiring blood transfusion. During the next weeks, neurologic symptoms developed, including hypertonia and increased deep tendon reflexes. During the next months he was continued on oral substitution with sodium bicarbonate. His physical and psychomotoric development were satisfactory, and only one additional hemolytic crisis occurred. At the time blood and urine were taken the patient was $1 \mathrm{y}$ of age, and his psychomotoric development was found to be appropriate for age.

In both patients, screening for inborn errors of metabolism revealed massive excretion of 5-oxoproline in urine (Table 1). Diagnosis of GSD was established by analyzing glutathione synthetase activity in extracts of cultured fibroblasts (Table 1). The enzyme activity in patient 2 was considerably higher than in patient 1 but well below our controls, including heterozygotes. As an adequate control group for studies of LT metabolism, eight healthy children (ages ranged between 1-3 y) were included into the study.

Glutathione, 5-oxoproline, and glutathione synthetase analysis. Erythrocyte total glutathione was measured by the 5,5'-dithiobis (2-nitrobenzoic acid)-glutathione recycling assay according to 
Table 1. Concentrations of erythrocyte glutathione, nonprotein thiols in whole blood, urinary 5-oxoproline, and glutathione synthetase activity in patients with GSD

\begin{tabular}{lccc}
\hline & Patient 1 & Patient 2 & $\begin{array}{c}\text { Controls } \\
(n=8)\end{array}$ \\
\hline $\begin{array}{l}\text { Erythrocyte glutathione } \\
(\mathrm{mM})\end{array}$ & 0.51 & 0.43 & $2.36 \pm 0.37$ \\
$\begin{array}{l}\text { Nonprotein thiols in whole } \\
\text { blood (mM) }\end{array}$ & 0.15 & 0.18 & $0.95 \pm 0.21$ \\
$\begin{array}{l}\text { 5-oxoproline in urine } \\
\text { (mol/mol creatinine) }\end{array}$ & 7.14 & 3.50 & $<0.05$ \\
$\begin{array}{l}\text { Glutathione synthetase in } \\
\text { fibroblasts (pkat/mg pro- }\end{array}$ & 1.6 & 11.6 & $33.2 \pm 8.3^{*}$ \\
tein) & & & \\
\hline$* n=9$. & & &
\end{tabular}

Anderson (11). The concentration of nonprotein thiols in whole blood was determined by adding $50 \mu \mathrm{L}$ of venous blood to 500 $\mu \mathrm{L}$ of $\mathrm{H}_{2} \mathrm{O}$ for hemolysis followed by protein precipitation with $750 \mu \mathrm{L}$ of $0.21 \mathrm{M}$ metaphosphoric acid $(1.67 \mathrm{~g}$ of metaphosphoric acid, $0.2 \mathrm{~g}$ of $\mathrm{Na}_{2}$ EDTA, $30 \mathrm{~g}$ of $\mathrm{NaCl}, \mathrm{H}_{2} \mathrm{O}$ up to $100 \mathrm{~mL}$ ); after mixing and centrifugation $(10 \mathrm{~min}, 10000 \times \mathrm{g}), 200 \mu \mathrm{L}$ supernatant was mixed with $800 \mu \mathrm{L}$ of $0.3 \mathrm{M} \mathrm{Na}_{2} \mathrm{HPO}_{4}$ and $100 \mu \mathrm{L}$

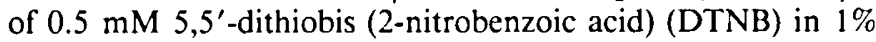
sodium citrate. The concentration of thiols was calculated on the basis of the change in absorbance at $412 \mathrm{~nm}$ (12). The 5 oxoproline was determined by capillary gas chromatographymass spectrometry (13). Glutathione synthetase activity in extracts of cultured fibroblasts was analyzed as described (14). Fibroblasts from nine control subjects, including children and adults, were analyzed for glutathione synthetase. The enzyme activity was found to be not age dependent.

Measurement of lipoxygenase products and $P G E_{2}$ in stimulated neutrophils and monocytes. Neutrophils and mononuclear cells were isolated as previously described $(15,16)$. The percentage of neutrophils in the cell preparations exceeded $97 \%$, and cell viability as determined by trypan blue exclusion was more than $98 \%$. Of the $2 \times 10^{6}$ adherent mononuclear cells per plate, 87 to $92 \%$ were monocytes as determined by their structure after staining with safranin or Giemsa. Neutrophils and monocyte monolayers were activated with calcium ionophore (final concentration, $10 \mu \mathrm{M}$; Sigma Chemical Co., St. Louis, MO) for 15 $\min$ at $37^{\circ} \mathrm{C}(15,16)$.

For analysis of $\mathrm{LTC}_{4}$ and $\mathrm{LTB}_{4},\left[{ }^{3} \mathrm{H}\right] \mathrm{LTC}_{4}$ and $\left[{ }^{3} \mathrm{H}\right] \mathrm{LTB}_{4}(\mathrm{Du}$ Pont-New England Nuclear, Boston, MA) were added to the cell supernatants as internal standards. Samples were pumped through activated Sep-Pak $C_{18}$ cartridges (Waters, Milford, MA). The cartridges were washed with distilled water and eluted with $5 \mathrm{~mL} 90 \%$ aqueous methanol containing $1 \mathrm{mM}$ 4-hydroxy2,2,6,6-tetramethylpiperidine-N(1)-oxyl (Sigma Chemical Co.) and $0.5 \mathrm{mM}$ EDTA. The eluates were evaporated to dryness under reduced pressure and resuspended in $30 \%$ ice-cold aqueous methanol. The samples were then injected into a $\mathrm{C} 18$ Hypersil column $(4.6 \times 250 \mathrm{~mm}, 5-\mathrm{mm}$ particle size, Shandon, Runcorn, UK) and eluted isocratically through an HPLC system (Knauer, Berlin, Germany) at a constant flow rate of $1 \mathrm{~mL} / \mathrm{min}$, with a mixture of acetonitrile/water (38:62, vol/vol), the aqueous part containing $0.1 \%$ acetic acid, $1 \mathrm{mM}$ EDTA, adjusted to $\mathrm{pH} 5.6$ by ammonium hydroxide. The fractions having the same elution time as synthetic LT were collected, and immunoreactive LT content was determined by ELISA (Cayman, Ann Arbor, MI). Each LT value was corrected for $\left[{ }^{3} \mathrm{H}\right] \mathrm{LT}$ recovery. The ELISA protocol has already been described in detail (17). Calculation of the standard curve regression and LT concentrations was carried out after a linear log-logit transformation (18).

The 5-, 12-, 15-HETE and $5 S, 12 S$-di-HETE in the supernatants of stimulated cells were analyzed by HPLC and UV spectrophotometry (19). Briefly, a mixture of phosphate buffer (17 $\mathrm{mM}$ dipotassium hydrogenphosphate, containing $0.05 \%$ EDTA, adjusted to $\mathrm{pH} 5.0$ with phosphoric acid), acetonitrile and methanol (50:30:20, vol/vol) was used to separate cysteinyl LT, $\mathrm{LTB}_{4}$, and $5 S, 12 S$-di-HETE at $280 \mathrm{~nm}$. Solvent change was performed at $34 \mathrm{~min}$ to a mixture of phosphate buffer $(6 \mathrm{mM}$ dipotassium hydrogenphosphate, containing $0.05 \%$ EDTA, adjusted to $\mathrm{pH}$ 5.0 with phosphoric acid), acetonitrile, and methanol (28:42:30, $\mathrm{vol} / \mathrm{vol}$ ). Wavelength switch was performed at $38 \mathrm{~min}$ to 235 $\mathrm{nm}$, which allowed simultaneous analysis of the mono-HETE 5-, 12-, and 15-HETE. Lipoxygenase products were quantified by peak areas. Standard curves of the individual substances were obtained with seven different concentrations (1-500 ng). Correlation coefficients of the different lipoxygenase products were always greater than 0.980 .

For analysis of $\mathrm{PGE}_{2},\left[{ }^{3} \mathrm{H}\right] \mathrm{PGE}_{2}$ (DuPont-New England Nuclear, Boston, MA) was added as internal standard. After SepPak extraction, HPLC purification was carried out with $40 \mathrm{mM}$ formic acid, $\mathrm{pH} 3.15$, with triethylamine-acetonitrile $(67: 33$, vol/ vol) as mobile phase under the conditions described above. Quantification of $\mathrm{PGE}_{2}$ was performed by ELISA (Cayman).

Incubation of isolated cells with ${ }^{\beta}$ H]LTA $4 .\left[{ }^{3} \mathrm{H}_{\mathrm{LTA}} \mathrm{LT}_{4}\right.$ was purchased as methyl ester (DuPont-New England Nuclear) and purified to more than $98 \%$ as shown by radio-HPLC. It was saponified in $20 \mathrm{~mL}$ of ethanol/1 N NaOH $(1: 1 \mathrm{vol} / \mathrm{vol})$ at $23^{\circ} \mathrm{C}$ for $30 \mathrm{~min}$ before use. Aliquots of this mixture were added directly to isolated neutrophils or monocytes. Incubations were carried out as described (20). After centrifugation and evaporation to dryness, the residue was taken up in isopropanol, acidified to pH 3 with $5 \mathrm{M}$ formic acid, and extracted with diethyl ether. After separation and addition of $10 \mathrm{mM}$ ammonium hydroxide after evaporation, the residue was adjusted to $\mathrm{pH} 9$ by ammonium hydroxide. The mixture was extracted on Sep-Pak cartridges, and analysis was performed by HPLC as described above. Eluent was monitored for radioactivity using a Raytest radioactivity detector (Raytest, Straubenhardt, Germany). Quantification of radioactivity was carried out by collection of fractions from the HPLC and analysis in a Beckman scintillation spectralphotometer (Beckman Instruments, Fullerton, CA).

Urinary $L T E_{4}$ analysis. Urine was obtained from spontaneous micturition, screened for the presence of pathologic constituents, and mixed with two volumes of $90 \%(\mathrm{vol} / \mathrm{vol})$ aqueous methanol of $\mathrm{pH} 8.5$ containing $0.5 \mathrm{mM}$ EDTA, $1 \mathrm{mM}$ 4-hydroxy-2,2,6,6tetramethylpiperidine-N(1)-oxyl, and $20 \mathrm{mM} \mathrm{KHCO}_{3}$. $\left[{ }^{3} \mathrm{H}_{\mathrm{LTE}}\right.$ (DuPont-New England Nuclear) was added as an internal standard, and the samples were acidified to $\mathrm{pH} 4.5$ by the addition of $0.1 \mathrm{M} \mathrm{HCl}$. Urinary $\mathrm{LTE}_{4}$ was measured after extraction on SepPak cartridges and HPLC purification with a methanol/water $(65: 35, \mathrm{vol} / \mathrm{vol})$ system by $\operatorname{ELISA}(8,21)$.

\section{RESULTS}

Glutathione and nonprotein thiols. As shown in Table 1, the concentration of total glutathione in erythrocytes of both patients represented approximately $20 \%$ of control values. The results were confirmed by measuring the levels of nonprotein thiols in whole blood, which normally consist of more than $95 \%$ of erythrocyte GSH.

Lipoxygenase products in neutrophils and monocytes. As demonstrated in Tables 2 and 3 , marked reduction in synthesis of $\mathrm{LTC}_{4}$ was observed in neutrophils and monocytes of the patients with GSD compared with controls. $\mathrm{LTB}_{4}$ synthesis, however, was highly increased in both cell types of the patients. Other lipoxygenase products, including 5-HETE, 5S,12S-di-HETE, and 12-HETE, were found to be within the values obtained for controls. The 15-HETE was below the detection limit $(<1.0 \mathrm{ng} /$ $10^{6}$ cells) in both cell types, whereas 12-HETE was below the detection limit in stimulated monocytes. $\mathrm{PGE}_{2}$ formation in both cell types of the patients was found to be within the lower range of control values.

Metabolism of ${ }^{\beta} H J L T A_{4}$ into ${ }^{\beta} H J L T C_{4}$ by neutrophils and monocytes. In neutrophils of both patients, drastically reduced 
Table 2. Formation of lipoxygenase products and $P G E_{2}$ in neutrophils after stimulation with calcium ionophore A23187 in patients with $G S D^{*}$

\begin{tabular}{lccc}
\hline & Patient 1 & Patient 2 & $\begin{array}{c}\text { Controls } \\
(n=8)\end{array}$ \\
\hline LTC $_{4}$ & 0.4 & 0.7 & $5.0 \pm 0.9$ \\
LTB $_{4}$ & 316.4 & 305.9 & $43.2 \pm 5.1$ \\
5-HETE & 40.6 & 45.1 & $38.7 \pm 6.4$ \\
5S,12S-di-HETE & 17.0 & 18.1 & $15.1 \pm 6.2$ \\
12-HETE & 9.5 & 8.9 & $7.3 \pm 2.1$ \\
PGE $_{2}$ & 0.05 & 0.06 & $0.09 \pm 0.02$ \\
\hline
\end{tabular}

* Results are expressed as $\mathrm{ng} / 10^{6}$ cells.

Table 3. Formation of lipoxigenase products and $P G E_{2}$ in monocytes after stimulation with calcium ionophore A23187 in patients with GSD*

\begin{tabular}{lrrr}
\hline & Patient I & Patient 2 & $\begin{array}{c}\text { Controls } \\
(n=8)\end{array}$ \\
\hline LTC $_{4}$ & 3.6 & 4.5 & $30.2 \pm 3.3$ \\
LTB $_{4}$ & 335.1 & 360.4 & $48.7 \pm 4.5$ \\
5-HETE & 38.7 & 40.6 & $33.2 \pm 8.9$ \\
5S,12S-di-HETE & 27.9 & 25.4 & $21.5 \pm 4.0$ \\
PGE $_{2}$ & 1.2 & 1.3 & $1.8 \pm 0.4$ \\
\hline
\end{tabular}

* Results are expressed as $\mathrm{ng} / 10^{6}$ cells.

Table 4. Endogenous urinary $L_{T E}$ in patients with GSD

\begin{tabular}{lccc} 
& Patient 1 & Patient 2 & $\begin{array}{c}\text { Controls } \\
(n=8)\end{array}$ \\
\hline $\mathrm{LTE}_{4}(\mathrm{pmol} / \mathrm{L})$ & 5 & 8 & $265 \pm 58$ \\
$\mathrm{LTE}_{4}(\mathrm{nmol} / \mathrm{mol}$ creatinine $)$ & 0.4 & 0.6 & $23 \pm 6$ \\
\hline
\end{tabular}

capacity to form $\left[{ }^{3} \mathrm{H}\right] \mathrm{LTC}_{4}$ could be observed $(9 \%$ of control values in patient 1 and $13 \%$ in patient 2). Analogous experiments performed in monocytes confirmed the marked reduction in formation of $\left[{ }^{3} \mathrm{H}\right] \mathrm{LTC}_{4}$, which was found to be $12 \%$ and $14 \%$, respectively, in the patients with GSD compared with control values.

Excretion of endogenous urinary $L T E_{4}$. Urinary $\mathrm{LTE}_{4}$ levels of patients and controls are given in picomoles per liter and nanomoles per mole creatinine (Table 4). Both patients showed an abnormally low urinary $\mathrm{LTE}_{4}$ concentration, which was decreased by a factor of 50 when compared with controls.

\section{DISCUSSION}

Our results demonstrate that $\mathrm{LTC}_{4}$ synthesis is severely decreased in monocytes and neutrophils of patients with GSD. The in vivo production of $\mathrm{LTC}_{4}$ by $\mathrm{LTC}_{4}$ synthase seems to depend on appropriate levels of intracellular GSH serving as a substrate in this reaction. This hypothesis is supported by the finding that the synthesis of $\mathrm{LTC}_{4}$ by mouse peritoneal macrophages can be selectively inhibited by depletion of intracellular stores of GSH (22). It cannot be excluded, however, that the stability of $\mathrm{LTC}_{4}$ synthase itself is affected if the levels of GSH fall below a critical limit. A similar mechanism where low levels of GSH might lead to secondary enzyme deficiencies has been described for erythrocyte glutathione-S-transferase in patients with erythrocyte GSD (23). Furthermore, deficiency of fumarylacetoacetate lyase activity was reported in the liver of a patient with GSD who died (24).

Decreased in vitro $\mathrm{LTC}_{4}$ synthesis by stimulated neutrophils and monocytes in GSD were further confirmed by the failure of these cells to metabolize $\left[{ }^{3} \mathrm{H}\right] \mathrm{LTA}_{4}$ into $\left[{ }^{3} \mathrm{H}\right] \mathrm{LTC}$. This finding supports previous studies performed in platelets of two siblings with GSD (20).

GSH is also needed for the formation of $\mathrm{PGE}_{2}$, which regulates 5-lipoxygenase and is used as an antiinflammatory compound (10). We therefore studied $\mathrm{PGE}_{2}$ synthesis in GSD. In contrast to $\mathrm{LTC}_{4}, \mathrm{PGE}_{2}$ synthesis by blood cells was only slightly reduced in GSD. The mechanism by which $\mathrm{PGE}_{2}$ synthesis can be maintained in GSD requires further investigation.

Formation of $\mathrm{LTB}_{4}$ was found to be highly increased in GSD. This finding reflects the block in the $\mathrm{LTC}_{4}$ formation from $\mathrm{LTA}_{4}$ leading to an increased conversion of $\mathrm{LTA}_{4}$ to $\mathrm{LTB}_{4}$. However, even if this overflow mechanism resulted in higher $\mathrm{LTB}_{4}$ levels, other 5-lipoxygenase products (5-HETE) and products derived from the 12- and 15-lipoxygenase pathways $(5 S, 12 S$-di-HETE, 12-HETE, and 15-HETE) were not affected (Tables 2 and 3).

Urinary $\mathrm{LTE}_{4}$ has been proposed and used as index metabolite for the systemic generation of cysteinyl LT in human beings ( 8 , 25). The low concentrations of urinary $\mathrm{LTE}_{4}$ in GSD (Table 4) reflect the fact that GSH deficiency in GSD not only leads to deficient $\mathrm{LTC}_{4}$ synthesis in vitro but also to a decreased generation of cysteinyl LT in vivo.

Because LT may play a role as modulators of central nervous activity and neuroendocrine events $(26,27)$, a pathophysiological link between impaired LT synthesis and clinical symptoms in GSD seems likely.

Recent studies have indicated that GSH esters are transported into many cells and split intracellularly to release GSH $(28,29)$. Therefore, further insight into cellular linkage between LT synthesis and GSH might be achieved by administration of GSH esters in GSD.

\section{REFERENCES}

1. Jellum E, Kluge T. Borresen HC, Stokke O. Eldjarn L 1970 Pyroglutamic aciduria-A new inborn error of metabolism. Scand J Clin Lab Invest 26:327335

2. Wellner VP, Sekura R, Meister A, Larsson A 1974 Glutathione synthetase deficiency, an inborn error of metabolism involving the $\gamma$-glutamyl cycle in patients with 5-oxoprolinuria (pyroglutamic aciduria). Proc Natl Acad Sci USA 71:2969-2972

3. Larsson A 1988 Hereditary disorders relating to glutathione deficiency. In: Dolphin D, Paulson R, Avramovic O (eds) Coenzymes and Cofactors. John Wiley \& Sons, New York, pp 197-233

4. Meister A, Larsson A 1989 Glutathione synthetase deficiency and other disorders of the $\gamma$-glutamyl cycle. In: Scriver CR. Beaudet AL, Sly WS, Valle D (eds) The Metabolic Basis of Inherited Disease. McGraw Hill, New York. pp 855-868

5. Beutler E, Dale GL 1988 Erythrocyte glutathione: function and metabolism. In: Dolphin D. Avramovic O. Poulson R (eds) Coenzymes and Cofactors. Vol 3: Glutathione. Part B. John Wiley \& Sons, New York, pp 291-317

6. Lewis RA, Austen KF 1984 The biologically active leukotrienes: biosynthesis. metabolism, receptors, functions, and pharmacology. J Clin Invest 73:889897

7. Samuelsson B, Dahlén S-E, Lindgren A, Rouzer CA. Serhan CN 1987 Leukotrienes and lipoxins: structures, biosynthesis, and biological effects. Science 237:1171-1176

8. Huber M, Müller J, Leier I, Jedlitschky G, Ball HA, Moore KP, Taylor GW. Williams R, Keppler D 1990 Metabolism of cysteinyl leukotrienes in monkey and man. Eur J Biochem 194:309-315

9. Maltby NH, Taylor GW, Ritter JM, Moore K. Fuller RW, Dollery CT 1990 Leukotriene $\mathrm{C}_{4}$ elimination and metabolism in man. J Allergy Clin Immunol $85: 3-9$

10. Ogino N, Miyamoto T. Yamamoto S. Hayaishi O 1977 Prostaglandin endoperoxide $\mathrm{E}$ isomerase from bovine vesicular gland microsomes, a glutathionerequiring enzyme. J Biol Chem 252:890-895

11. Anderson ME 1985 Determination of glutathione and glutathione disulfide in biological samples. Methods Enzymol 113:548-555

12. Beutler E 1984 Red Cell Metabolism. Grune \& Stratton, Orlando. FL. pp 131134

13. Hoffmann G. Aramaki S, Blum-Hofmann E. Nyhan WL. Sweetman L 1989 Quantitative analysis for organic acids in biological samples: batch isolation followed by gas chromatographic-mass spectrometric analysis. Clin Chem 35:587-595

14. Larsson A, Mattson B. Hagenfeldt L, Moldeus P 1983 Glutathione synthetase deficient human fibroblasts in culture. Clin Chim Acta 135:57-64

15. Weller PF. Lee CW. Foster DW, Corey EJ. Austen KF, Lewis RA 1983 Generation and metabolism of 5-lipoxygenase pathway by human eosinophils: predominant production of leukotriene $C_{4}$. Proc Natl Acad Sci USA $80: 7626-76,30$

16. Williams JD, Czop JK, Austen KF 1984 Release of leukotrienes by human 
monocytes on stimulation of their phagozytic receptor for particulate activators. J Immunol 132:3034-3040

17. Antoine C, Lellouche JP, Maclouf J, Pradelles P 1991 Development of enzyme immunoassays for leukotrienes using acetylcholinesterase. Biochim Biophys Acta 1075:162-168

18. Pradelles P, Grassi J, Maclouf J 1990 Enzyme immunoassay of eicosanoids using acetylcholinesterase. Methods Enzymol 77:24-34

19. Knöller J, Schönfeld W, Köller M, Hensler T, König W 1988 Arachidonic acid metabolites from polymorphonuclear leukocytes of healthy donors, severely burned patients and children with cystic fibrosis: routine monitoring by highperformance liquid chromatography. J Chromatogr 427:199-208

20. Pace-Asciak CR, Klein J, Spielberg SP 1986 Human genetic defect in leukotriene $C_{4}$ synthesis. Biochem Biophys Res Commun 140:857-860

21. Mayatepek E, Lehmann W-D, Fauler J, Tsikas D, Frölich JC, Schutgens RBH, Wanders RJA, Keppler D 1993 Impaired degradation of leukotrienes in patients with peroxisome deficiency disorders. J Clin Invest 91:881-888

22. Rouzer CA, Scott WA, Griffith OW, Hamill AL, Cohn ZA 1981 Depletion of glutathione selectively inhibits synthesis of leukotriene $\mathrm{C}$ by macrophages. Proc Natl Acad Sci USA 78:2532-2536

23. Beutler E, Gelbart T, Pegelow C 1986 Erythrocyte glutathione synthetase deficiency leads not only to glutathione but also to glutathione-S-transferase deficiency. J Clin Invest 77:38-41

24. Gray RGF, Lloyd AJ, Green A 1992 Fumarylacetoacetate lyase enzyme stability and its relevance in tyrosinaemia type 1 and glutathione synthetase deficiency. 30th Annual Symposium of the Society for the Study of Inborn Errors of Metabolism, Leuven, Belgium, September 8-11, 1992, p 17(abstr)

25. Keppler D. Huber M. Hagmann W, Ball HA. Guhlmann A, Kästner S 1988 Metabolism and analysis of endogenous cysteinyl leukotrienes. Ann NY Acad Sci 524:68-74

26. Lindgren JA, Hökfelt T, Dahlén SE, Patrono C. Samuelsson B 1984 Leukotrienes in the rat central nervous system. Proc Natl Acad Sci USA 81:62126216

27. Hulting AL, Lindgren LA, Hokfelt T, Eneroth P, Werner S, Patrono C, Samuelsson B 1985 Leukotriene $\mathrm{C}_{4}$ as a mediator of luteinizing hormone release from rat anterior pituitary cells. Proc Natl Acad Sci USA 82:38343838

28. Puri RN, Meister A 1983 Transport of glutathione, as $\gamma$-glutamyl cysteinylglycyl ester, into liver and kidney. Proc Natl Acad Sci USA 80:5258-5260

29. Wellner VP, Anderson ME, Puri RN, Jenssen GL, Meister A 1984 Radioprotection by glutathione ester: transport of glutathione ester into human lymphoid cells and fibroblasts. Proc Natl Acad Sci USA 81:4732-4735 